\title{
Research on Single Chip Computer Teaching Reform under CDIO Engineering Education Mode
}

\author{
Fuyan Zhang ${ }^{a}$, Chunjun Zheng ${ }^{\text {b }}$ \\ Department of Computer Science and Technology, Dalian Neusoft University of Information, Dalian, \\ 116023, China \\ aemail: zhangfuyan@neusoft.edu.cn, ${ }^{\mathrm{b} e m a i l}$ :zhengchunjun@neusoft.edu.cn
}

Keywords: CDIO; Teaching methods; Teaching Reform

\begin{abstract}
The feature of single chip computer course is theoretical weakness, but strong practical and high requirements for engineering practice ability. Nowadays, the teaching methods in single chip computer exist a series of drawbacks. Under CDIO engineering education mode, for training of brilliant single chip computer system development engineer, exploration and research of teaching reform in single chip computer course has been implemented and achieved good results.
\end{abstract}

\section{Introduction}

With the rapid development of modern science and technology, single chip computer has become increasingly broad applications in the field of automation control, intelligent instrument, medical equipment, household appliances, etc. Almost all of Mechanical and electrical specialties in universities set up the course in order to meet the basic needs of industry. The course plays a crucial role in training brilliant single chip computer engineers.

Our school is the two of the College, and committed to the cultivation of IT talents. In recent years, teaching reform under CDIO engineering education mode is implemented. To cultivate "industry-oriented" single chip computer application engineers with excellent engineering qualities and abilities, who already "have a year of experience" in school, and can be able to be seamless convergence with enterprise demand, exploration and research of teaching reform in single chip computer course has been carried out.

\section{Single Chip Computer Course Teaching Status and Weaknesses}

\section{A. Emphasis on Theory but Light Practice}

Single chip computer course should cover theory, and focus more on practice. But in the current implementation process of teaching, teachers are dominant in class. They often take the spoon-feeding way of teaching, instilling theory in full lesson. Even with examples to explain the analysis, it usually can not be visually presented owing to the equipment condition limit. So students can only become passive recipients, rarely having the opportunity of practice. Even they master the principles and development theory of single chip computer, but can not verify and digest it in practice, which often result in the predicament of "empty talk". Students are either difficult to start the development process in a actual system, or full of mistakes and can not locate the key.

Single chip computer system development is not only software programming control, but also includes hardware circuit analysis, design and debug, etc. Nowadays, the practice in single chip computer course is to train students the ability of program, rarely involve the culture of other important abilities and qualities.

B. the Arrangement of Chapters is Unreasonable.

At the beginning of the course, the traditional single chip computer teaching is too focused on assembly instruction system and assembly language, which is boring and difficult for students whose foundation is weaker. It's easy, in that case, to produce school-weary psychology, and hit their confidence and interest to continue learning [1]. In fact, the assembly language is just a tool to realize the single chip computer system control. For starters, the language tool is difficult and 
complex to operate, it can be taken over by others such as $C$ language. Students can go back to learn how to use assembly language to do the promotion and expansion after a certain foundation and experience of the single chip computer working principle and programming control.

At the beginning of the course, the traditional single chip computer teaching generally tends to focus on the structure of single chip computer, including CPU structure, memory organization, the structure and function of pin, single chip computer timing, clock resetting circuit, etc. [2] Students need to accept such boring and abstract principle when the single chip computer is new to them. As a result, they are tired of learning for lack of the understanding of the visual image, which absolutely is harmful to stimulate and develop the learning enthusiasm. In addition, teachers often focus on explaining the C51-related knowledge, lots of which can be used in a relatively long time and is easy to forget.

\section{Practice Equipment Drawbacks}

Although there is practice arrangement in single chip computer course in every universities and specialties, it often takes the same traditional form: arranging a fixed special laboratory, purchasing a complete set of experiment box and students doing experiments at scheduled time. The experimental methods are usually has the following disadvantages.

The modules on experiment box have been fully encapsulated or partially encapsulated. The electric circuit wiring is almost hidden in the panel below, even the key interface and driver chips are not visible. The most things visible in the pane are pin holes and connection slots for extension. Due to the technical secrecy factors, with lack of supporting information such as circuit schematic, it's hard for students to get a global understanding of the principle and control of modules in use, and the experimental results obtained are not very good. The wire connections in experimental box have already been completed in the time when designed and the reserved interface is limit. Students just need to experiment according to descriptions and step requires with simple wire connections or no connections, but it's limited that students can only complete and ran some confirmatory procedures [3]. For example, in Marquee experiment, it may only be able to use CPU port to connect with light-emitting diodes. There is no way to take other connections and control. It's difficult to complete comprehensive experiments with this device, and not conducive to culture students' initiative and innovation because of the lack of flexibility.

The resources in experiment box are abundant, but the electric circuit is often complicated. Usually, it can not fully meet the needs of teaching, and it can not appropriately fit the teaching materials and teaching contents. So it's not very suitable for starters to use.

Students can only enter the laboratory and use experiment box in fixed time according to arrangement. There are a series of problems limit to laboratory opening time, experiment place, equipment and many other conditions. Students can not use experiment box immediately after the explanation of theory knowledge and not all knowledge can be tested in the experimental box. The experiment box size is often too large to carry conveniently, and it's not allowed to be taken out of laboratory. Students can only finish the experiment on schedule. If they have met some difficulties and can't finish on time, the only thing they can do is choosing giving up. Of course, it's more difficult for them to take some innovation and exploration experiment by themselves after class.

The hardware of experiment box purchased has been ensured to be correct before students using it. Even some breakdowns occur in the using process, it also will be returned to factory to repair. And students are lack of the engineering practice ability cultivation of hardware electric circuit debugging and combined debugging of hardware and software.

\section{Single Chip Computer Teaching Reform and Exploration}

\section{A. Project-Driven Teaching}

Under CDIO engineering education mode, project-driven method is taken in order to organize teaching by "project-guided" way, following which a course project and a serial of unit projects are designed. Course project tries to cover the more knowledge points the better, and the unit projects covers part of knowledge points. At the beginning of course, the course project is introduced and analyzed as guidance for students to understand clearly what knowledge and skills they have to 
master, and what abilities they have to culture in class. Course teaching is no longer taken by chapter in the traditional way, but by course project to expend and process layer by layer throughout the course. Unit projects are realized one by one and integrated together continuously with the course project promoting, and in the end, the integrated unit projects form the course project [4][5].

In the project implementation process, it's needed to pay attention to the followings.

In order to stimulate students' interest in learning, and avoid the fear of difficulties, an easy start is needed. It's better to reduce the entry threshold and not spread theory knowledge crowded together. With reducing the explanation of theory, it's must strengthen the abilities of understanding, thinking, applying and developing of knowledge. For example, the course doesn't start with details of single chip computer structure. It's enough for students to know how to use single chip computer's I/O port, and can realize I/O port input/output. Other content will be gradually introduced in time when needed [6].

Student is the main part in class, and teacher just plays a role of facilitator [7]. Teacher starts the project, and then guides students to analysis, design and implement the project by themselves. Teacher can use ways in the process: inquiry teaching method: teacher guide students to discover and solve problems by themselves; case teaching method: teacher use case and organize students to discuss and work out the project plan; experimental teaching method: teachers guide students to use the experimental device to run project, and observe the visual phenomenon and the change, by which way students acquire knowledge; cooperative teaching method: students learn in group cooperation.

In the process of implementing course project step by step, teacher should guide students to integrate the unit projects finished before. At last, a integrated course project can be formed from a series of simple unit projects gradually. In fact, the process of integrating is the develop process of a complex-comprehensive single chip computer system. This process can train students to obtain the ability of system analysis, modular design, architecture design, system implementation and debugging and other critical abilities for project practice.

In order to evaluate students learning fairly, assessment methods must be improved. A certain number of projects would better to be evaluated in this course, and teacher gives each student score for per project according to the process of project, project result and project report. Although teacher's workload increased much, it can urge students to behave well in usual study, and it can also help teacher to know well the problems in the teaching process and make appropriate adjustments timely.

B. Improving Practice

Single chip computer is a course which needs lots of practice and operation. A good single chip computer system development engineer needs not only Solid theoretical knowledge ,but also the practice abilities such as circuit analysis and design, software and hardware debug etc. under engineering education mode, in order to train students' practice abilities and qualities, the traditional practice must be improved.

The first step, author designed a circuit board with base but complete function modules, which includes matrix keyboard, DIP switch, LED, LCD, electric relay, 8255 and ADC0809 resource etc. every module is independent, and they need to be connected together by wires in a project. every single chip computer knowledge point, such as I/O port operation, timer/counter, interrupt, commonly used equipment interface resource etc, can be practiced and verified on board. The advantage of this board comparing to traditional experimental box is: (1) simple structure but complete functions is fit to starters. (2) It is smart for carrying on, and fit to use in class. (3) It has abundant reserved interface, and can be connected flexibly. With the marquee project as an example like before, light-emitting diodes can be either connected directly with I/O port, or connected with a serial-to-parallel chip as well as 8255 . So even a simple marquee can have different control modes because of different hardware connections [8].

The second step, teacher offer students the blank board. Students buy components themselves and go into laboratory for welding and debugging the circuit board. this step is not only to enable students to know the various types of components and understand the hardware circuit principle, but 
also to cultivate them hardware circuit debugging ability .

The third step, students carry on the circuit board in class. After the introduction of theoretical knowledge points, "strike white the iron is hot", students can practice with the board at once. In that way, theory and practice is combined closely, which allow "learning to doing", and "doing to learning" to come true [9].

The fourth step, in the teaching process, students are required to use the reserved interface on board for expansion of function module and realizing control. This focuses on training the students' self-learning and innovation ability.

C. Integration of Teaching and Competition

It also takes "Learn to Apply and Apply to Promote Learning" in practice. Students are encouraged to participate in community and SOVO virtual corporation after class, and they are encouraged to innovative and “competition to learn”. through competition and some of the practical application of product development, it not only enable students to firmly master professional and core knowledge of single chip computer, but also cultivate and train students' ability of engineering practice and innovation. The personnel trained in this way are just demanded by industry. In addition, the practice of the former students is a rich material accumulated for next student, and teacher can adjust teaching content according to the development of the industry in time, that can ensure seamless integration with industry.

\section{Conclusion}

The single chip computer course makes a series of reform and exploration under CDIO education mode, and has obtained good teaching effect. Students have the engineering abilities and qualities needed by embedded industry, and become qualified to be single chip computer application engineers.

\section{References}

[1] X. J. Liu, "Exploration of Single-Chip Computer Teaching in higher Vocational College", Value Engineering, no. 21, Jul. 2011, pp.68-73.

[2] W. C. Xie, "Principle and Application of MCU \& C Programming”, Tsinghua University Press, 2009, pp.10-20.

[3] S. Wu, Y.H. Zhang, "Reform and Exploration of Single -Chip Computer Experiment Teaching in University”, J. Da Zhong Ke Ji, no. 11, Nov. 2011, pp.194-205.

[4] Y. Lian, “ Reform of Single Chip Computer Practical Course under CDIO Education Mode”, Consumer Electronics, Sep. 2012, pp.194-205.

[5] X. Y. Zhang, "brief Discussion of Teaching Reform in Single Chip Computer Course”, Higher Vocational-Journal of Tianjin Professional College, vol. 16, no. 01, Feb. 2011, pp.40-41.

[6] T. X. Guo, "New Concept of 51 Single-Chip C Language Tutorial- Introduction, Development, Expand, Improve”, Electronic Industry Press, 2009, pp.1-50.

[7] R. Tao, "Research on Role Changes of Teachers in Vocational Colleges under CDIO Engineering Education Model”, Journal of Naning Polytechnic, vol.18, no. 01, Jan. 2013, pp.55-57.

[8] X. R. Sun, and J. R Zhou, "the Development of Equipment in Program-based Training in Single-Chip Computer Teaching”, Journal of Jiujiang Vocational \& Technical College, no. 04, Dec. 2011, pp.19-20.

[9] J. Z. Zha, "on CDIO Model under "Learning by Doing" Strategy”, Research in Higher Educaion of Engineering, no. 3, May. 2008, pp.1-9. 